
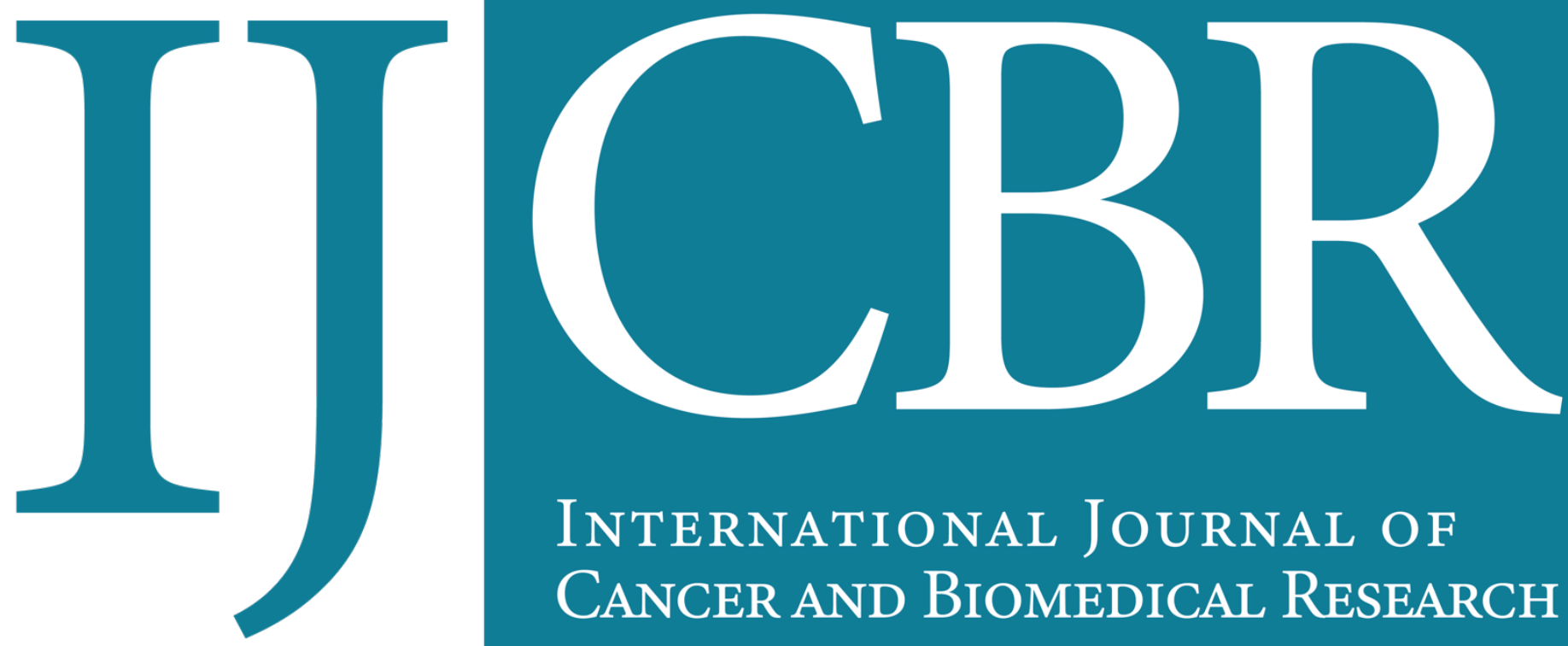

INTERNATIONAL JOURNAL OF CANCER AND BIOMEDICAL RESEARCH

https://jcbr.journals.ekb.eg

Editor-in-chief

Prof. Mohamed Labib Salem, PhD

Long term survival outcome of childhood acute lymphoblastic leukemia treated with modified TXIIIB protocol at South Egypt Cancer Institute

Azza Shibl, Heba A Sayed, Amany M Ali, Dalia O. Mohamed and Omnia N. Abdelhamid 


\title{
Long term survival outcome of childhood acute lymphoblastic leukemia treated with modified TXIIIB protocol at South Egypt Cancer Institute
}

\author{
Azza Shibl ${ }^{1}$, Heba A Sayed ${ }^{1}$, Amany M Ali ${ }^{1}$, Dalia O. Mohamed ${ }^{2}$ and Omnia N. Abdelhamid ${ }^{1}$ \\ ${ }_{1}^{1}$ Pediatric Oncology, South Egypt Cancer Institute, Assiut University, Assiut, Egypt \\ ${ }^{2}$ Radiation Oncology, South Egypt Cancer Institute, Assiut University, Assiut, Egypt
}

\section{ABSTRACT}

II ARTICLE INFO

Background: The survival of children with acute lymphoblastic leukemia (ALL) has greatly improved in recent decades. Aim: We aimed at evaluating the outcome of children with ALL and their prognostic factors. Materials \& Methods: A prospective study included 200 newly diagnosed pediatric ALL patients from 2009 to 2017 . All patients were treated according to the modified total therapy study XIIIB for higher risk ALL adopted from St. Jude Children's Research hospital (SJCRH), USA. Results: Favorable age $(<10 \mathrm{y})$ and total leucocytic count (TLC) $(\geq 50 \times 10 \% / \mathrm{L})$ occurred in $75 \%$ and $69 \%$, respectively. B-precursor ALL represented $82.5 \%$. Central nervous system (CNS) involvement occurred in $4.5 \%$. High-risk patients represented $47 \%$. Complete remission was achieved in $92.5 \%$ and was significantly affected by the early morphologic response of BM d15, while it wasn't related to the phenotype. Eightyear overall survival, disease-free survival, and event-free survival were $77 \pm 3 \%, 70$ $\pm 4 \%$, and $66 \pm 3 \%$, respectively. Adverse events included induction deaths (4.5\%), refractory leukemia $(3 \%)$, relapse $(23.2 \%)$, secondary $A M L(0.5 \%)$, and deaths in remission (3.5\%). By multivariate analysis, unfavorable age group $\geq 10$ years, hyperleukocytosis, and patients with slow early response were the only ones associated with unfavorable impact on the outcome. There was statistical significant difference between standard and high risk for B-precursor ALL but not for Tprecursor ALL. Conclusion: We concluded that treating children with ALL through modified TXIIIB protocol improved the survival at our institute than previous and the early response to treatment has a strong implication on the outcome.

Keywords: Acute lymphoblastic leukemia; Childhood; long term; South Egypt Cancer Institute; Survival

Editor-in-Chief: Prof. M.L. Salem, Ph.D. - Article DOI: 10.21608/jcbr.2021.59346.1126

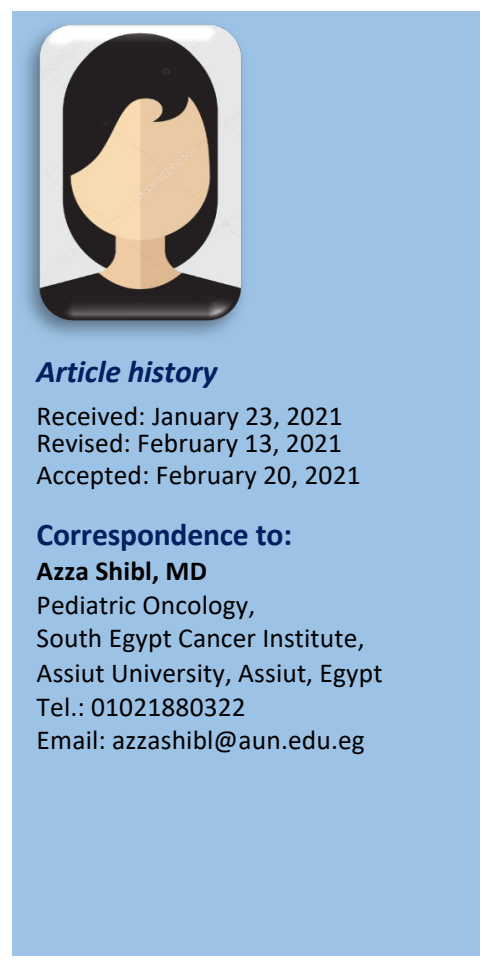

\section{INTRODUCTION}

The long-term survival rate of pediatric acute lymphoblastic leukemia (ALL) patients has greatly improved to reach and even exceed $90 \%$ in many developed countries in recent years, especially for groups with good prognoses. This improvement is mainly due to the strategies of modifications in therapy based on patients' pharmacodynamics and pharmacogenomics, risk-adapted therapy, and improved supportive care (Vrooman et al., 2013; Stary et al., 2014; Pui et al., 2015; Mourtada et al., 2020).

Several prognostic factors of survival outcome were identified including clinical, biological, and genetic characteristics such as age and gender, total leucocytic count (TLC) at diagnosis, immunophenotypic, cytogenetic, and molecular characteristics (Friedmann and Weinstein, 2000; Möricke et al., 2005; Pui et al., 2008). Nevertheless, Treatment itself remains one of the strongest prognostic factors, as shown in well-designed large clinical trials, with the early response to treatment is highly predictive for patients' outcomes that allowed several studies to integrate it in risk stratification (Schrappe et al., 2000; Lauten et al., 2012).

In developing countries, several challenges are influencing treatment outcomes. Delayed presentation, lack of adequate supportive therapy, incompliance, shortage of chemotherapeutic agents, abandonment of 
therapy, and genetic variations may contribute to a negative prognosis (Rodriguez-Galindo et al., 2015; Antillón et al., 2017; Abdelmabood et al., 2020).

Local control of the disease in the central nervous system (CNS) is an essential part of the treatment of ALL. at the time of diagnosis of ALL, Overt CNS involvement accounts for only 3-5\% of patients (Pizzo and Poplack, 2015). Previously, CNS-directed therapy was achieved by irradiation of the whole neuraxis with a dose of 24 Gray (Gy) (Hill et al., 2004). With the establishment of the effectiveness of intensified chemotherapy especially high dose methotrexate (HDMTX) in controlling CNS disease, studies succeeded in minimizing the need for prophylactic cranial irradiation from high-risk leukemia to a more limited group of high-risk leukemia by early intensification treatment with intensified early intrathecal (Schrappe et al., 2000; Pui et al., 2004). Further progress was reported in the results of TXV studies that showed success in improving overall survival without the need for prophylactic cranial irradiation (Pui et al., 2009).

Children with ALL at our institute were treated with a modified protocol of Berlin, Frankfurt, Muenster (BFM) trials with cranial radiotherapy to all high-risk patients. The outcome of children with ALL was unsatisfactory (Khalifa et al., 2005). In 2009, we started treating patients with ALL according to modified TXIIIB protocol adopted from the St. Jude Children Research Hospital (SJCRH) (Pui et al., 2004). In this study, we aimed at studying the long-term outcome of children with ALL at our department with the determination of the different prognostic factors affecting it.

\section{MATERIAL AND METHODS}

A prospective study was carried out on 200 newly diagnosed pediatric ALL patients who were presented to Pediatric Oncology Department, South Egypt Cancer Institute (SECI), Assiut University from January 2009 till January 2017. The study was reviewed and approved by the institutional review board and ethical committee and informed consent was obtained from the patients' parents or guardians. Newly diagnosed patients with ALL from 1- $<18$ years were included. Children who have received steroids for more than 3 days or chemotherapy before enrollment into the study were excluded. Also, patients who died very early during the first week of diagnosis were excluded.

\section{Diagnosis}

Diagnosis of ALL was based on morphologic and cytochemical evaluation of bone marrow (BM) smears as well as immunophenotyping of leukemic blast cells (based on WHO classification) (Swerdlow, 2008). For diagnosis of CNS status of patients, cerebrospinal fluid (CSF) was drawn through lumbar puncture at day one of induction treatment after prophase (four days of steroid) to avoid traumatic CSF. CNS involvement was defined according to Smith's classification; as the presence of leukemic cells with five white blood cells or less per microliter of CSF diagnose CNS involvement (Smith et al., 1996).

\section{Risk stratification \& Treatment}

Patients were classified into standard and high risk, according to National Cancer Institute $\mathrm{NCl} /$ Rome criteria; standard risk: age 1- < 10 with $\mathrm{TLC}<50 \times 109 / \mathrm{L}$ and high risk: all other patients, including patients with CNS leukemia at diagnosis (Smith et al., 1996).

All patients were treated according to modified total therapy study XIIIB for ALL of SJCRH for higher risk (Pui et al., 2004). Treatment included induction phase with a six-drug regimen (vincristine, prednisone, asparaginase, daunorubicin, cytarabine, and etoposide) for 29 days preceded by four days of steroid (prophase) to reduce tumor burden gradually. The induction of remission phase was followed by BM aspiration and CSF cytology to evaluate post induction response. Patients who underwent complete remission (CR) passed to consolidation phase with two doses of HDMTX, $2 \mathrm{~g} / \mathrm{m} 2 \mathrm{IV}$ given via a 2-hour infusion, and then all patients passed to continuation for higher risk ( 120 weeks for female \&146 weeks for male) consisted of 8 weeks of drug pairs administered in a weekly rotation and repeated sequential manner till the end of continuation including etoposide/ cyclophosphamide, intramuscular methotrexate (IM MTX)/ mercaptopurine (6MP), IM MTX/ cytarabine, vincristine/ 
dexamethasone, etoposide/cyclophosphamide, HDMTX/ 6MP, etoposide/ cytarabine and vincristine/ dexamethasone (Pui et al., 2004). The dose of etoposide was reduced from 300 $\mathrm{mg} / \mathrm{m} 2$ to $150 \mathrm{mg} / \mathrm{m} 2$ at the continuation therapy to minimize the incidence of second malignancy and it was replaced with oral 6-MP for 7 days after week 53. Also, HDMTX was replaced by IM MTX after week 53 to reduce its late effects. A reinduction phase for 6 weeks was given starting on week 16 of continuation therapy and consisted of vincristine $1.5 \mathrm{mg} / \mathrm{m} 2$ IV, weeks 16, 17, 18, 19; daunorubicin 25 $\mathrm{mg} / \mathrm{m} 2 \mathrm{IV}$, weeks 16, 17; asparaginase 10,000 $\mathrm{U} / \mathrm{m} 2 \mathrm{IM}$, every other day for 6 doses; dexamethasone $8 \mathrm{mg} / \mathrm{m} 2 /$ day, weeks 16 through 19; HDMTX given on weeks 20\& 21, with calcium leucovorin rescue; 6-MP 75 $\mathrm{mg} / \mathrm{m} 2$ daily during two weeks of HDMTX intake; and triple intrathecal (TIT) according to age, week 21 . Triple IT was given every 8 weeks during the first 53 weeks (for CNSII). Subgroups of patients with CNS leukemia at diagnosis, TLC $\geq 100 \times 109 / L$, T-cell ALL, and TLC $\geq 50 \times 109 / L$ received IT therapy every 4 weeks during the first 53 weeks of continuation (CNSIII or CNS directed therapy). Cranial irradiation was administered only to T-cell ALL and $\geq 100 \times 109 / \mathrm{L}$ or CNS leukemia at diagnosis ( $18 \mathrm{GY}$, plus 5 intrathecal treatments from weeks 56 to 59 ).

\section{Supportive measures}

Prophylaxis against Pneumocystis carinii pneumonia with trimethoprim and sulfa meth oxazole combination was given to all patients twice daily for 3 consecutive days per week from day 15 of remission induction to 6 weeks after completion of all chemotherapy. Oral Mycostatin as antifungal prophylaxis also was started from the start of induction. Treatment of fever neutropenia was according to our established protocol. Assessing and supplementing patients who presented or developed malnutrition during therapy with oral or parenteral nutrition. Supplementation with packed red blood cells and platelet transfusion according to guidelines

\section{Evaluation and follow up}

Bone marrow aspirate was done to evaluate response to chemotherapy on day 15 of induction to assess early response, post- induction following one week after completion of remission of induction therapy than during continuation treatment. CSF cytology was aspirated at the same time of BM aspiration. Bone marrow status in D15 or post-induction is classified into M1 ( $<5 \%$ blasts), M2 $(<25 \%$ blasts) or $M 3$ ( $\geq 25 \%$ blasts) remaining in the bone marrow (Lanzkowsky et al, 2016). M1 response on day 15 was classified as a rapid early response (RER) and patients who showed M2 \&M3 response were classified as a slow early response (SER) (Khan et al, 2020). Complete remission was defined as a normocellular BM containing less than $5 \%$ blast cells and showing evidence of normal maturation of other marrow elements. Complete remission was defined as $<5 \%$ blasts in $\mathrm{BM}$ together with hematologic recovery \& no extramedullary disease. Induction failure was defined as $\geq 25 \%$ blasts (Lanzkowsky et al., 2016). Patients who survived after failing the induction of remission were considered refractory leukemia.

\section{Statistical analysis}

Cut off point of the study was March 2017. Statistical analysis was carried out using SPSS statistical software version 21. Qualitative data were expressed as frequency and percentage; quantitative data were expressed by mean \pm standard deviation and median. Groups was compared using Chi-square/ Fisher's exact tests. Survival rates were calculated according to Kaplan and Meier method and Log-rank test was used to compare between groups. The overall survival (OS) was calculated from the date the patient enrolled in the study to the date of death from any cause or the date of the last follow-up. Disease-free survival (DFS) was measured from the end of induction for patients who achieved CR (induction deaths and nonresponder were excluded) to the time of relapse or date of the last follow-up. Event-free survival (EFS)was measured from the date of CR to the date of first treatment failure of any kind (relapse, death in CR, ALL lineage switch, second malignancy, or lost follow-up) or the date of the last follow up. Multivariate analysis was used to find the independent prognostic factors using Cox-regression test. P-value $<0.05$ was considered significant. 


\section{RESULTS}

During the study period, 230 pediatric patients who were newly diagnosed as ALL were reported at the South Egypt cancer institute. Only 200 patients were eligible for enrollment into the study. The remaining 30 patients were excluded due to very early deaths before starting induction therapy (15 patients), previous history of steroid intake before diagnosis (7 patients), previous chemotherapy ( 3 patients) and 5 patients referred for other centers on demand.

\section{Patient characteristics}

Table 1 shows the characteristics of the 200 eligible pediatric patients with ALL and their relation to immunophenotyping. The median age of the patients was 5 years ranged from 116 years; 150 patients $(75 \%)$ of them were less than 10 years. Male predominance $(60 \%)$ was noted with a male: female ratio of 1.5: 1 .

Most patients had initial TLC of $\geq 50 \times 10^{9} / \mathrm{L}$ (31\%), 33 patients of them (52.3\%) had $\geq 100 \times 10^{9} /$ L. B- Precursor ALL reported in 165 patients $(82.5 \%)$ and $\mathrm{T}$ - precursor ALL in 35 patients (17.5\%). It was found that $65.7 \%$ of Tprecursor ALL had an Initial TLC of $\geq 50 \times 10^{9} / \mathrm{L}$ compared to only $23.6 \%$ of B- Precursor ALL (P $<0.0001)$. CNS involvement was reported in only $4.5 \%$ of patients at diagnosis. High-risk patients represented $47 \%$ (94 patients) including $80 \%$ of T- precursor ALL and only $40 \%$ of B- Precursor ALL $(P<0.0001)$.

\section{Induction of remission response}

On day 15 , only 157 patients, 130 B-precursor ALL\& 27 T-precursor ALL, could undergo the procedure and be evaluated for BM morphologic response. Rapid early response was achieved in137 patients (87.3\%) while twenty patients $(12.7 \%)$ had SER. There was no significant relation of the slow early response to the patients' immunophenotyping as 14/130 of them (10.8\%) were B- precursor ALL and 6/27 patients $(22.2 \%)$ were $T$ - precursor $A L L(P=$ 0.104)].

Induction remission was achieved in 185 out of 200 patients $(92.5 \%)$ [152/165 (92\%) were Bprecursor ALL and $33 / 35$ (94.3\%) were Tprecursor ALL]. Of the remaining patients, $6(3 \%)$ had induction failure (all were B-ALL) and 9 (4.5\%) patients died during induction (7 of them were B-ALL). The phenotype was found to have no statistically significant effect on induction response $(P=0.593)$. on the other hand, among the 20 patients who showed SER, 2 patients $(10 \%)$ failed to achieve complete remission in comparison to only 2 of $137(1.5 \%)$ patients with RER and 2 patients (10\%) for those who showed slow SER died during induction versus $2.2 \%$ $(3 / 137)$ for those showed RER $(P=0.002)$. as regards the nine deaths during induction, they were due to infectious complications (fulminant bacterial pneumonia (5 patients), aspergillosis with massive hemoptysis ( 2 patients), and sepsis (2 patients).

\section{Central nervous system-directed therapy}

Forty-four (22\%) patients were subjected to CNS-directed therapy; twenty (10\%) patients, of them were treated with cranial irradiation in addition to frequent TIT.

\section{Survival}

At a mean follow up period of 50 months ranged between 3- 97 months, treatment failure was reported in 66 (33\%) patients as following, 9 (4.5\%) induction deaths, 6(3\%) refractory leukemia, 43 (21.5\%) relapses, 2ry AML in one patient $(0.5 \%)$ at 23 months from diagnosis, and 7(3.5\%) patients died in continuous complete remission (CCR) due to infectious causes. the remaining 134 (67\%) patients were living in CCR. Among the 43 patients with relapse, 26 (13\%) patients had isolated medullary relapse, $12(6 \%)$ patients isolated CNS relapse, $3(1.5 \%)$ patients with combined relapses and $2(1 \%)$ patients had an ocular relapse. All the relapses were reported within the first 3.5years after diagnosis. Thirty-one (18.8\%) patients of B- ALL precursors and 12 (34.3\%) patients of T- ALL precursors had relapsed. sixteen patients after relapse died due to disease progression. Eightyear OS was $77 \pm 3 \%$, 8 - year DFS was $70 \pm 4 \%$, and 8- year EFS was $66 \pm 3 \%$ (Figures 1, 2, and 3, respectively).

Analysis of prognostic factors that may influence patients' survival revealed that both risk stratification and early response at day 15 significantly affected all survival rates (OS, DFS, and EFS) of the study group with unfavorable 
impact associated with a high-risk group and slow early response. Age $\geq 10$ years and hyperleukocytosis (TLC $\geq 100 \times 109 / L$ ) had a statistically significant unfavorable impact on both DFS and EFS. Borderline unfavorable impact on DFS has been reported with TPrecursor ALL $(P=0.050)$. Other factors as CNS leukemia and sex had an insignificant impact on patients 'survival as shown in Table 2.

Significance of $\mathrm{NCl}$-risk stratification on DFS was evident on patients with B-precursor ALL (8year DFS was $85 \pm 5 \%$ for standard risk and $69 \pm 8 \%$ for high risk $(p=0.012)$ ) (Figure 4$)$ but this was not the case for T-precursor ALL patients (8-year DFS was $85.7 \%$ for standard risk and $57.7 \%$ for high risk $(P=0.310))$. On multivariate analysis, SER was the only factor that significantly affected OS $(P<0.001)$, age $\geq$ 10 years and SER affected EFS $(P<0.001)$ and age $\geq 10$ years $(P<0.001)$, SER $(P<0.001)$ in addition to hyperleukocytosis $(P=0.04)$ affected DFS.

\section{DISCUSSION}

This is a prospective study that was undertaken at the Pediatric Oncology Department, SECl, Assiut University as an example of a tertiary center for cancer treatment in a developing country with limited resources. We aimed at determining the long-term treatment outcome of children with ALL using the modified TXIIIB ALL protocol adopted from SJCRH. After a mean follow-up period of 50 months for our cohort, we report a dramatic improvement in survival rates of our patients ( 8-year OS and EFS were $77 \pm 3 \%$ and $66 \pm 3 \%$ respectively) compared to earlier results (4-year OS was 39 $\pm 5 \%$ ) reported by our colleagues (Khalifa et al, 2005).

Our results show that children with age $<10$ years represented most cases (75\%) with a median age of 5 years. This is similar to several reports from both developed (Schrappe et al, 2000; Pui et al., 2010) and developing countries (Bachir et al, 2009; Mushtaq et al, 2013). This comes in correspondence to major periods of industrialization in developed countries with exposure to new environmental leukemogens (Hrušák et al., 2002) and infection based two theory models in developing countries as infections are commensurate with increased lymphoid-cell proliferation (Kinlen, 2004; Greaves, 2006).

Male predominance in our study (60\%) confirms what is known of higher incidence of ALL among boys than the girls and the percentage is near to that reported in all developed and developing countries; $58.3 \%$ at SJCRH (Pui et al, 2004), 59\% in Morocco (Bachir et al., 2009), 65.3\% in Pakistan (Mushtaq et al., 2013), 55.2-61.8\% in $\mathrm{NCl}$-Egypt (Aliedin, 2010) and (64\%) in the previous study in SECI (Khalifa et al., 2005).

Precursor T-cell ALL has been reported as $17.5 \%$ in our study. Its incidence was varied among studies; the low incidence in BFM studies (12\% to $13.9 \%$ ) (Schrappe et al., 2000), $14 \%$ to $17 \%$ in total therapy studies of SJCRH (Pui et al, 2004) and $13 \%$ to $19.9 \%$ in Children's Cancer Group (CCG) trials (Gaynon et al., 2000). On the other hand, most studies from developing countries have reported a high incidence where it ranged from 29.5-52.8\% in India (Rajalekshmy et al., 2011), 21.15\% in Morocco (Bachir et al, 2009) and $24.2 \%$ in a cancer children hospital and $\mathrm{NCl}$, Egypt (Sidhom et al., 2013). This wide range of difference attributes primarily to environmental factors linked to socioeconomic status and patterns of infections in infancy (Ramot and Magrath, 1982; Greaves et al., 1993).

Compared to the TXIIIB study of SJCRH (Pui et al, 2004); we report a higher incidence of high-risk features for CNS relapse among our patients. CNS involvement at diagnosis was $2.8 \%$ vs $4.5 \%$ respectively, and TLC $\geq 50 \times 109 / \mathrm{L}$ was $(26.7 \%$ vs $31 \%$ respectively) with $16.5 \%$ had $\geq 100 \times 109 /$ L vs $15.4 \%$ of patients at SJCRH and the slight increase of T-ALL phenotype. Of course, this is attributed to the large discrepancy in the number of study groups, also it may be a sequel of late diagnosis of our patients. Post induction complete remission was achieved in $92.5 \%$ of our patients .Although it is lower than that reported in developed countries; $98 \%$ in SJCRH (Pui et al., 2004), but it's still comparable to others with similarly limited resources. In Guatemala, it was 92.9\% (Antillón et al., 2017) and $93.1 \%$ in $\mathrm{NCl}$, Egypt (Hussein et al., 2004). This decreased CR response is related mainly to high induction deaths $(4.5 \%)$ rather than incomplete remission (3\%). 
Table 1. Clinical and laboratory characteristics of patients with acute lymphoblastic leukemia in relation to immunophenotyping.

\begin{tabular}{|c|c|c|c|c|}
\hline & $\begin{array}{c}\text { Total } \\
(n=200)\end{array}$ & $\begin{array}{c}\text { B-precursor } \\
(n=165)\end{array}$ & $\begin{array}{c}\text { T-precursor } \\
(n=35)\end{array}$ & P-value \\
\hline $\begin{array}{l}\text { Age(years) } \\
\quad 1-<10 \\
\geq 10 \text { median(range) }\end{array}$ & $\begin{array}{l}150(75 \%) \\
50(25 \%) \\
5(1-16)\end{array}$ & $\begin{array}{l}126(76.4 \%) \\
39(23.6 \%)\end{array}$ & $\begin{array}{l}24(68.6 \%) \\
11(31.4 \%)\end{array}$ & 0.334 \\
\hline $\begin{array}{l}\text { Sex } \\
\quad \text { Males } \\
\text { Females }\end{array}$ & $\begin{array}{l}120(60 \%) \\
80(40 \%)\end{array}$ & $\begin{array}{l}94(57 \%) \\
71(43 \%)\end{array}$ & $\begin{array}{l}26(60 \%) \\
9(25.7 \%)\end{array}$ & 0.058 \\
\hline $\begin{array}{l}\text { CNS involvement } \\
\text { No } \\
\text { Yes }\end{array}$ & $\begin{array}{l}191(95.5 \%) \\
9(4.5 \%)\end{array}$ & $\begin{array}{l}158(95.8 \%) \\
7(4.2 \%)\end{array}$ & $\begin{array}{l}33(94.3 \%) \\
2(5.7 \%)\end{array}$ & 0.703 \\
\hline $\begin{array}{l}\operatorname{TLC}\left(\times 10^{9} / \mathrm{L}\right) \\
<50 \times 10^{9} / \mathrm{L} \\
\geq 50-100 \times 10^{9} / \mathrm{L} \\
\geq 100 \times 10^{9} / \mathrm{L}\end{array}$ & $\begin{array}{l}138(69 \%) \\
29(14.5 \%) \\
33(16.5 \%)\end{array}$ & $\begin{array}{l}126(76.4) \\
22(13.3 \%) \\
17(10.3 \%)\end{array}$ & $\begin{array}{l}12(34.3 \%) \\
7(20 \%) \\
16(45.7 \%)\end{array}$ & $<0.0001$ \\
\hline $\begin{array}{l}\text { Risk } \\
\text { Standard } \\
\text { High }\end{array}$ & $\begin{array}{l}106(53 \%) \\
94(47 \%)\end{array}$ & $\begin{array}{l}99(60 \%) \\
66(40 \%)\end{array}$ & $\begin{array}{l}7(20 \%) \\
28(80 \%)\end{array}$ & $<0.0001$ \\
\hline
\end{tabular}

ALL acute lymphoblastic leukemia, CNS central nervous system, and TLC total leucocytic count. $\mathrm{P}<0.05$

Table 2. Prognostic factors affecting survival rates of the study group

\begin{tabular}{|c|c|c|c|c|c|c|}
\hline & OS (\%) & $P$ value & DFS (\%) & $P$ value & EFS (\%) & $P$ value \\
\hline $\begin{array}{l}\text { Age: } \\
<10 \text { Ys } \\
\geq 10 \text { Ys }\end{array}$ & $\begin{array}{l}82.7 \% \pm 3 \\
74 \% \pm 6\end{array}$ & 0.162 & $\begin{array}{l}81.3 \% \pm 4 \\
60.9 \% \pm 8\end{array}$ & 0.003 & $\begin{array}{l}75.5 \% \pm 5 \\
63 \% \pm 8\end{array}$ & 0.059 \\
\hline $\begin{array}{l}\text { Sex } \\
\text { Male } \\
\text { female }\end{array}$ & $\begin{array}{l}78.3 \% \pm 3 \\
83.8 \% \pm 5\end{array}$ & 0.345 & $\begin{array}{l}78.2 \% \pm 5 \\
73.2 \% \pm 7\end{array}$ & 0.542 & $\begin{array}{l}72.7 \% \pm 5 \\
72 \% \pm 8\end{array}$ & 0.977 \\
\hline $\begin{array}{l}\text { CNS involvement: } \\
\text { Yes } \\
\text { No }\end{array}$ & $\begin{array}{l}81.2 \% \pm 3 \\
66.7 \% \pm 16\end{array}$ & 0.427 & $\begin{array}{l}76.8 \% \pm 4 \\
62.5 \% \pm 17\end{array}$ & 0.478 & $\begin{array}{l}72.9 \% \pm 4 \\
62.5 \% \pm 17\end{array}$ & 0.651 \\
\hline $\begin{array}{l}\mathrm{TLC}(\times 109 / \mathrm{L}) \\
<50 \times 109 / \mathrm{L} \\
\geq 50-<100 \times 109 / \mathrm{L} \\
\geq 100 \times 109 / \mathrm{L}\end{array}$ & $\begin{array}{l}84.8 \% \pm 3 \\
72.4 \% \pm 9 \\
69.7 \% \pm 12\end{array}$ & 0.075 & $\begin{array}{l}81.5 \% \pm 5 \\
75 \% \pm 12 \\
54.8 \% \pm 10\end{array}$ & 0.004 & $\begin{array}{l}76.9 \% \pm 5 \\
70.8 \% \pm 12 \\
54.8 \% \pm 11\end{array}$ & 0.032 \\
\hline $\begin{array}{l}\text { IPT } \\
\text { B-ALL } \\
\text { T-ALL }\end{array}$ & $\begin{array}{l}83 \% \pm 4 \\
68 \% \pm 9\end{array}$ & 0.056 & $\begin{array}{l}78.9 \% \pm 5 \\
63.6 \% \pm 9\end{array}$ & 0.050 & $\begin{array}{l}74.3 \% \pm 5 \\
63.6 \% \pm 9\end{array}$ & 0.171 \\
\hline $\begin{array}{l}\text { RISK } \\
\text { Standard } \\
\text { High }\end{array}$ & $\begin{array}{l}100 \% \pm 4 \\
70.4 \% \pm 5\end{array}$ & 0.050 & $\begin{array}{l}85.1 \% \pm 5 \\
65.5 \% \pm 6\end{array}$ & 0.002 & $\begin{array}{l}79.2 \% \pm 5 \\
64.3 \% \pm 6\end{array}$ & 0.021 \\
\hline $\begin{array}{l}\text { Early response } \\
\text { RER } \\
\text { SER }\end{array}$ & $\begin{array}{l}83.2 \% \pm 4 \\
45 \% \pm 11\end{array}$ & 0.000 & $\begin{array}{l}78.8 \% \pm 5 \\
50 \% \pm 13\end{array}$ & 0.002 & $\begin{array}{l}74.2 \% \pm 5 \\
50 \% \pm 13\end{array}$ & 0.013 \\
\hline
\end{tabular}

OS overall survival, DFS disease-free survival, EFS event-free survival, CNS central nervous system, TLC total leucocytic count, IPT immunophenotyping, RER rapid early response, SER slow early response. $p<0.05$ 


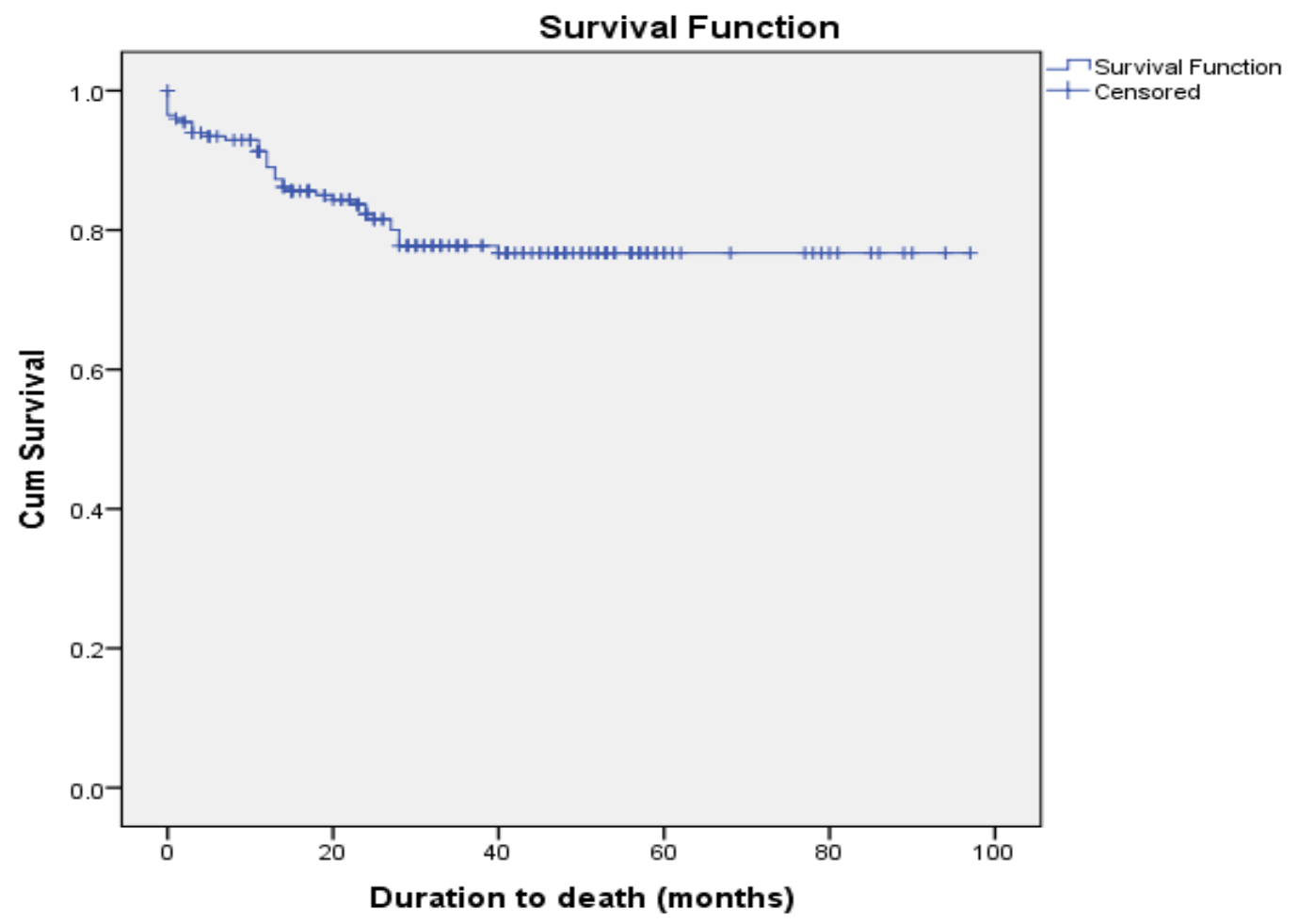

Figure 1. Eight-year overall survival for the study group (200 patients) was $77 \pm 3 \%$

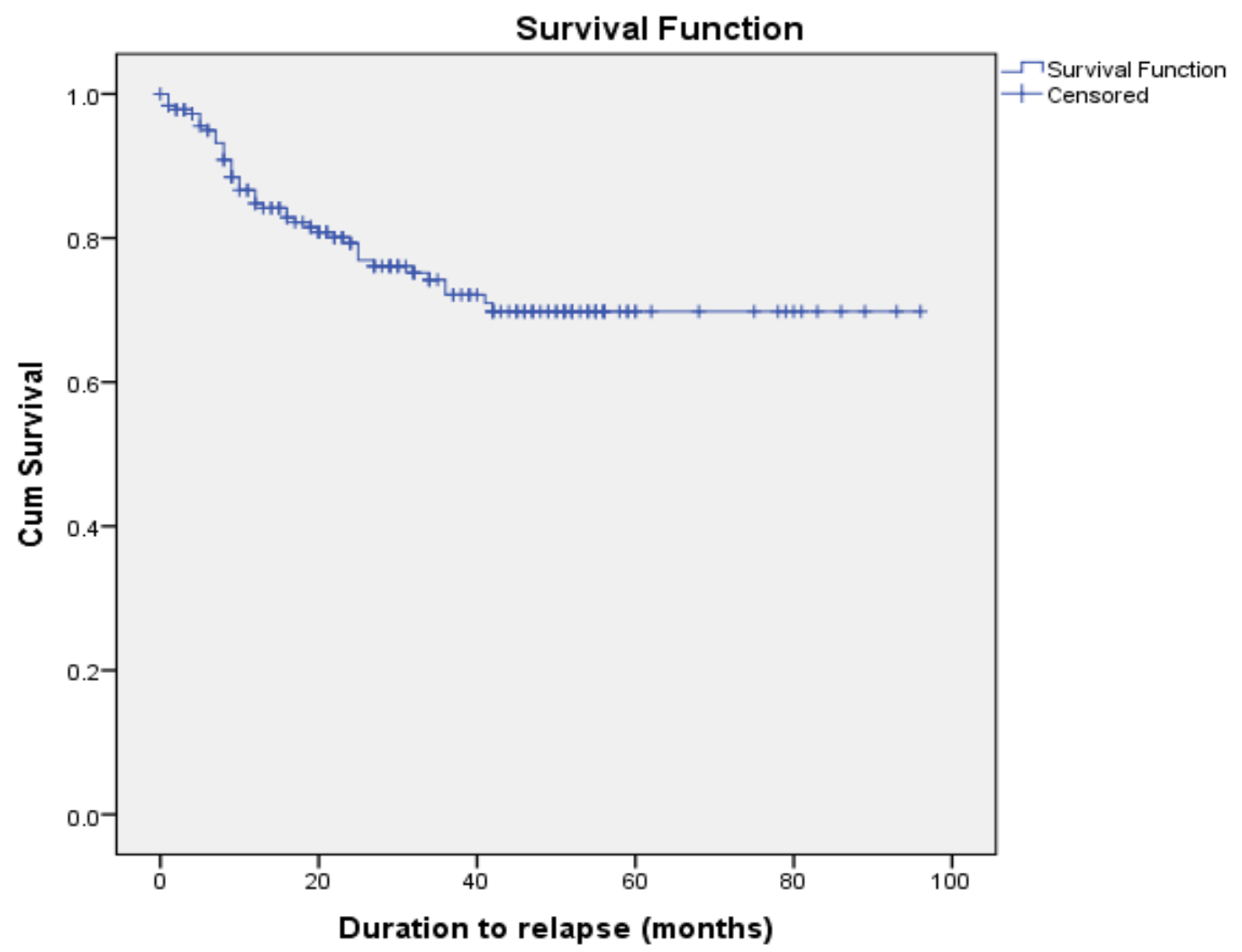

Figure 2. Eight-year disease-free survival for the study group (185patients) was $70 \pm 4 \%$ 


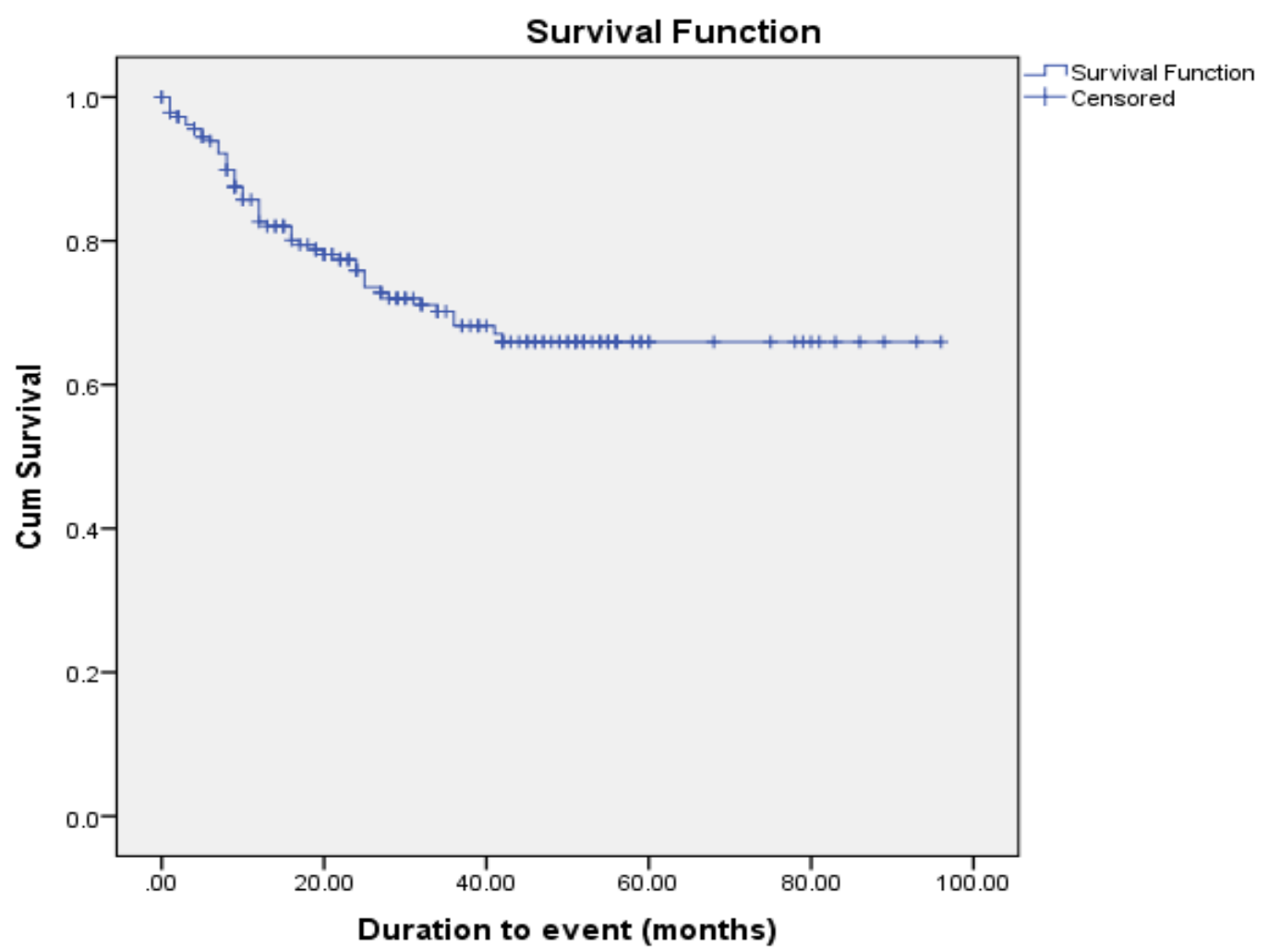

Figure 3. Eight-year event-free survival for the study group (185patients) was $66 \pm 3 \%$

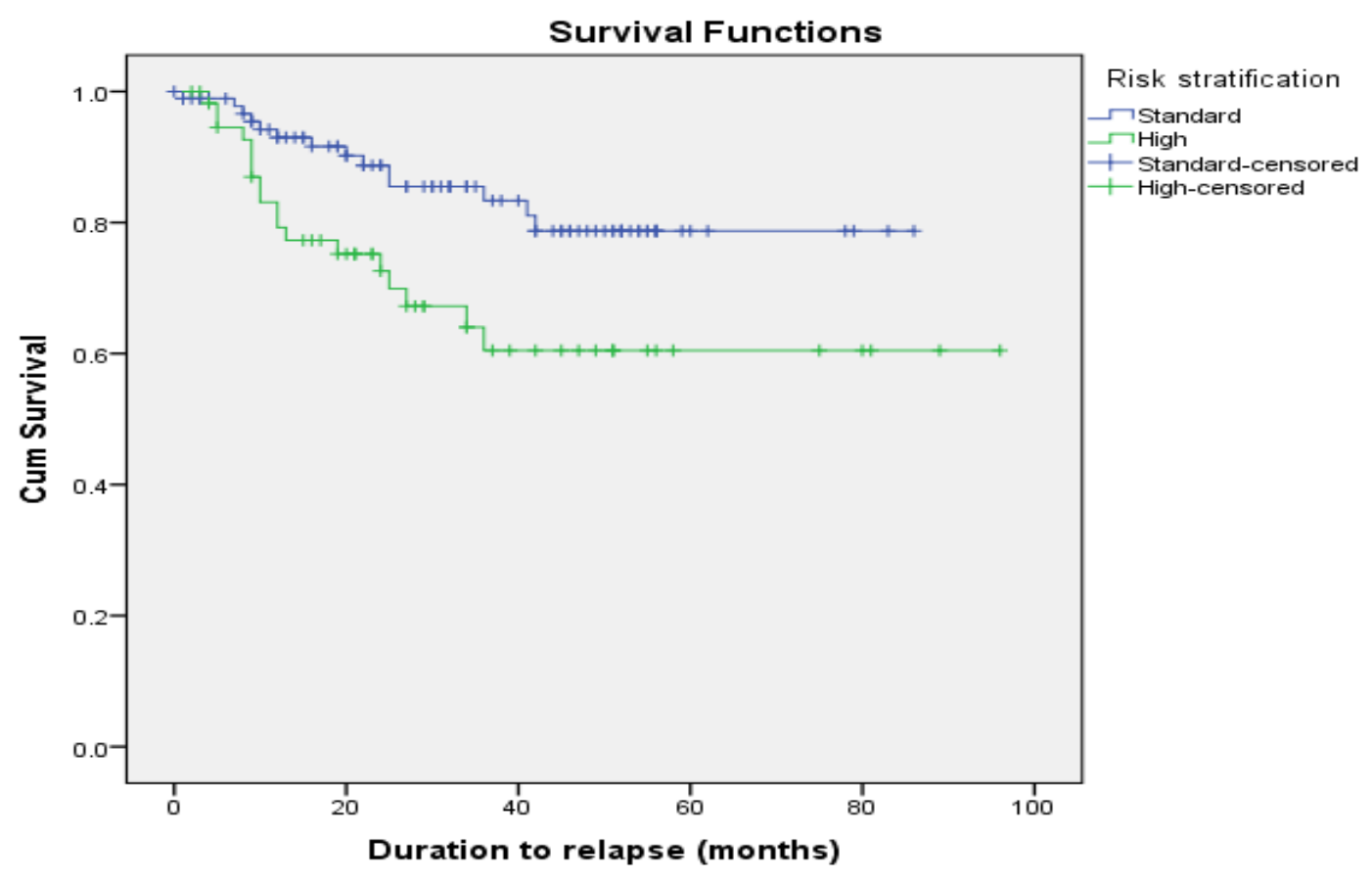

Figure 4. Eight-year disease-free survival for B-precursor ALL according to their $\mathrm{NCl}$ - risk classification (152 patients): 8- year DFS was $85 \%$ for standard risk and $69 \%$ for high risk $(P=0.01)$.

Our induction deaths were much higher than (1.2\%) that reported by Pui et al (Pui et al., 2004). However, it is less than those of the same limited resources (6.6\% and $5.8 \%$ respectively) (Hussein et al., 2004; Antillón et al., 2017). Also,
Deaths in CCR were $3.5 \%$ is higher than those reported for the TXIIIB cohort as 7 out of 247 (2.8\%) died in CR (Pui et al., 2004). the prophase with prednisone followed by induction chemotherapy allowed for gradual depletion of 
the leukemic cells with reduction of the risk of toxic death during induction as reported by Jabbar and his colleagues that induction deaths reduced from $14 \%$ to $9 \%$ by this regimen especially in those with high-risk leukemia (Jabbar et al., 2020).

As the induction deaths or deaths in CCR were mainly due to infectious complications, our concern should be directed to the best strategies for the prevention and treatment of infections to these patients rather than changes in chemotherapy.

We assessed early response at day 15 by bone marrow cytomorphologic response; $12.7 \%$ of the evaluable patients had SER which was much higher than $7.1 \%$ that reported by Hussein and his colleagues who treated patients on the same protocol (Hussein et al, 2004) and $7.6 \%$ of patients at SJCRH (Pui et al., 2004). We noted that SER among T-ALL patients in our results was nearly double those among B-ALL patients. Although this was non-significant, Lauten et al. confirmed the differential response of BM day 15 responses among different immunophenotyping when they studied the prognostic impact of BM response at day15 in comparison to prednisone response. They concluded that resistance to prednisone can be compensated by high sensitivity to other chemotherapeutic drugs in B-ALL patients or the reverse but this was not the case in T-ALL patients (Lauten et al., 2012).

Although the achievement of CR didn't differ in B-precursor ALL patients from those with T-ALL in our results ( $92 \%$ vs $94.3 \%$ respectively, $P=$ 0.5 ), it is significantly affected by early response reported at day 15 as $98.5 \%$ of patients with RER vs $90 \%$ of those with SER achieved CR ( $P=$ 0.002). Our results are comparable to results of the ALL BFM- 95 trial that reported an induction-remission rate of $100 \%$ in patients with RER (Lauten et al., 2012). Khan and his colleagues in Pakistan reported that only $43 \%$ of patients with SER achieved remission (Khan et al., 2020). This indicates that CR is mostly related to sensitivity to the chemotherapy besides the patients' characteristics as proved by systematic measurements of in vitro and in vivo drug resistance (Kaspers et al., 1997; Holleman et al., 2004).
It is well recognized that cranial irradiation can cause many major late complications, including second cancers, neurocognitive deficits, and endocrinopathy. Hence, the practice in modern clinical trials has been to limit the use of this treatment modality to patients with a particularly high risk of CNS relapse (Pui et al., 2003). Patients who received cranial irradiation in our study were lower than the contemporary protocol at SJCRH ( $10 \%$ vs $12 \%$ respectively) despite the higher incidence of the high-risk features for CNS relapse at diagnosis in our patients. This may be due to the higher early deaths during treatment of our patients.

Pui and his colleagues reported a significant decrease in CNS relapse (isolated and combined) from $6.1 \% \pm 1.3$ and $7.6 \% \pm 1.4$ respectively in 11 - protocol to $1.7 \% \pm 0.8$ and $3.3 \% \pm 1.2$ respectively in TXIIIB protocol and none in 14- protocol. They worked on the early intensification of intrathecal therapy and gradual reduction of cranial irradiation need till succeeded in eliminating cranial irradiation in TXV therapy study (Pui et al., 2010). We followed this strategy at our institute but still, the rate of CNS relapse is high $(6.6 \%$ isolated CNS relapse\& $1.7 \%$ combined relapse) among our patients. In an earlier study comparing the outcome of patients with high-risk T-precursor ALL treated with or without cranial irradiation, the 3-year CNS relapse rate was significantly higher amongst patients who did not receive cranial irradiation; $18 \%$ vs $7 \%$ in the irradiated group) $\mathrm{P}=0.012$ ). However, cranial irradiation had an insignificant impact on EFS (Laver et al, 2000). Their study wasn't on a randomized basis with higher median TLC and CNS involvement at diagnosis in the non-irradiated group. We couldn't relay the high incidence of CNS relapse in our study on the reduction of cranial irradiation. Reduced patients compliance and adherence to treatment may be the cause (Antillón et al., 2017). We can agree with this hypothesis as most events occurred during therapy during the first 3.5 years with a plateau survival curve after treatment.

Also, we reported a much higher incidence of overall relapse (23.2\%) than that among patients treated with the contemporary protocol at SJCRH (11.7\%) (Pui et al., 2004). While, it is slightly comparable to that of other 
low middle-income countries; $22.6 \%$ in Guatemala (Antillón et al., 2017) and 21.7\% (Mushtaq et al, 2013) and it is much lower than $38.9 \%$ that reported in a previous study on BFM trial in our institution (Khalifa et al., 2005).

Although a great success in improving the survival outcome of our patients compared to previous study at our department (8-year OS of $77 \pm 3 \%$ vs 4 -year OS was $39 \pm 5 \%$ respectively) (Khalifa et al., 2005), it still lower than results reported in developed countries. Our 8-year EFS rate was $66 \pm 3 \%$ compared to $80.8 \pm 2.6 \% 5$-year EFS for patients treated in the TXIIIB at SJCRH (Pui et al, 2004), $78 \pm 1 \%$ in BFM-90 study (Schrappe et al., 2000) and 75\% for patients treated on CCG trials (Gaynon et al., 2000).

The impact of early morphologic response was observed to be reflected on the survival of our cohort as SER showed an independent prognostic effect on survivals together with older age $(\geq 10)$ and hyperleukocytosis. Lauten and his colleagues studied the prognostic impact of BM response on day 15 and reported that the 8-year probabilities of EFS of patients with M1, M2, M3 day 15 morphologic marrow responses were $86.1 \%, 74.5 \%$ and $46.4 \%$ respectively. They also reported that BM response at day 15 predicted the outcome more than prednisone response in patients treated with ALL-BFM 95 trials. So, they allowed the addition of BM on Day 15 as risk stratification parameters (Lauten et al., 2012). This is well understood as the BM on Day 15 reflects the response to 14 days of induction chemotherapy and TIT MTX more than the response to prednisone only.

In conclusion, our survival outcome improved dramatically than the previous but still lower than that of developed countries. Early response to treatment has a strong impact on survival outcomes together with older age and hyperleukocytosis. There was a high death rate among our patients during the study period. So, we recommend the inclusion of the day 15 response in future risk stratification of our patients with an intensification of treatment for those with a slow response. Also, we recommend strict implementation of strategies for the management of fever neutropenia and supportive care that provide great help in this issue. Our limitations were the unavailability of minimal residual disease and cytogenetics for all patients allover the time due to financial effect hoping to be available in the future.

\section{CONFLICTS OF INTEREST}

All authors declare no conflicts of interest.

\section{FUND}

No fund was received for this work.

\section{REFERENCES}

Abdelmabood S, Fouda AE, Boujettif F, Mansour A (2020). Treatment outcomes of children with acute lymphoblastic leukemia in a middleincome developing country: high mortalities, early relapses, and poor survival. Jornal de Pediatria (Versão em Português), 96(1):108116.

Aliedin N. 2010. NCl hospital- based registry 2002(2010). Available at: http: // www.nci.cu.edu.eg. Accessed in March 2014. wwwncicuedueg.

Antillón FG, Blanco JG, Valverde PD, Castellanos M, Garrido CP, Girón V, Letona TR, Osorio EJ, Borrayo DA, Mack RA (2017). The treatment of childhood acute lymphoblastic leukemia in Guatemala: biologic features, treatment hurdles, and results. Cancer, 123(3):436-448.

Bachir F, Bennani S, Lahjouji A, Cherkaoui S, Khattab M, Nassereddine I, Zafad S, El Aouad R (2009). Characterization of acute lymphoblastic leukemia subtypes in Moroccan children. International Journal of Pediatrics.

Friedmann AM, Weinstein HJ (2000). The role of prognostic features in the treatment of childhood acute lymphoblastic leukemia. The oncologist, 5(4):321-328.

Gaynon P, Trigg M, Heerema N, Sensel M, Sather H, Hammond G, Bleyer W (2000). Children's Cancer Group trials in childhood acute lymphoblastic leukemia: 1983-1995. Leukemia, 14(12):2223-2233.

Greaves M. 2006. Infection, immune responses and the aetiology of childhood leukaemia. Nature Reviews Cancer, 6(3):193-203.

Greaves M, Colman S, Beard M, Bradstock K, Cabrera $M$, Chen $P$, Jacobs $P$, Lam-Po-Tang $P$, MacDougall L, Williams C (1993). Geographical distribution of acute lymphoblastic leukaemia subtypes: Second report of the collaborative group study. Leukemia, 7(1):27-34.

Hill FG, Richards S, Gibson B, Hann I, Lilleyman J, Kinsey S, Mitchell C, Harrison CJ, Eden OB, Leukaemia UMRCWPo C (2004). Successful treatment without cranial radiotherapy of children receiving intensified chemotherapy for 
acute lymphoblastic leukaemia: results of the risk-stratified randomized central nervous system treatment trial MRC UKALL XI (ISRC TN 16757172). British Journal of Haematology, 124(1):33-46.

Holleman $\mathrm{A}$, Cheok $\mathrm{MH}$, den Boer $\mathrm{ML}$, Yang $\mathrm{W}$, Veerman AJ, Kazemier KM, Pei D, Cheng C, Pui $\mathrm{C}-\mathrm{H}$, Relling MV (2004). Gene-expression patterns in drug-resistant acute lymphoblastic leukemia cells and response to treatment. New England Journal of Medicine, 351(6):533-542.

Hrušák O, Trka J, Zuna J, Poloučková A, Kalina T, Starý J (2002). Acute lymphoblastic leukemia incidence during socioeconomic transition: selective increase in children from 1 to 4 years. Leukemia, 16(4):720-725.

Hussein $H$, Sidhom I, Naga SA, Amin M, Ebied E, Khairy A, Kamel A, El-Sharkawy N (2004). Outcome and prognostic factors of acute lymphoblastic leukemia in children at the National Cancer Institute, Egypt. Journal of Pediatric Hematology/ Oncology, 26(8):507514.

Jabbar N, Mansoor N, Nadeem K, Butt Z, Ashraf S (2020). Prednisolone Prophase for a Week Versus Upfront Multiagent Chemotherapy in Childhood Acute Lymphoblastic Leukemia: An Analysis With Reference to Induction Mortality in a Developing Country. Journal of Pediatric Hematology/ Oncology, 42(3):181-184.

Kaspers G, Veerman A, Pieters R, Van Zantwijk C, Smets L, Van Wering E, Van Der Does-Van Den Berg A (1997). In vitro cellular drug resistance and prognosis in newly diagnosed childhood acute lymphoblastic leukemia. Blood, The Journal of the American Society of Hematology, 90(7):2723-2729.

Khalifa N, Abdel Hadi S, Ghazaly M (2005). The clinical significance of prognostic features in childhood acute lymphoblastic leukemia in South Egypt Cancer Institute [thesis results]. 64- 86. $p$.

Khan S, Anwar S, Latif MF, Farooq A, Faizan M (2020). Induction-remission response in peadiatric acute lymphoblastic leukaemia, Lahore protocol versus UKALL 2011 interim guidelines. JPMA The Journal of the Pakistan Medical Association, 70(4):591-596.

Kinlen L (2004). Infections and immune factors in cancer: the role of epidemiology. Oncogene, 23(38):6341-6348.

Lanzkowsky P, Lipton JM, Fish JD (2016). Lanzkowsky's manual of pediatric hematology and oncology: Academic Press.

Lauten $M$, Möricke $A$, Beier R, Zimmermann $M$, Stanulla M, Meissner B, Odenwald E, Attarbaschi A, Niemeyer C, Niggli F (2012).
Prediction of outcome by early bone marrow response in childhood acute lymphoblastic leukemia treated in the ALL-BFM 95 trial: differential effects in precursor B-cell and T-cell leukemia. Haematologica, 97(7):1048-1056.

Laver J, Barredo J, Amylon M, Schwenn M, Kurtzberg J, Camitta B, Pullen J, Link M, Borowitz M, Ravindranath $Y$ (2000). Effects of cranial radiation in children with high risk $T$ cell acute lymphoblastic leukemia: a Pediatric Oncology Group report. Leukemia, 14(3):369-373.

Mourtada FA, Assem MM, El Leithy A, Hassan NM, Hassan NH (2020). RUNX3 gene expression confers an independent Overall survival advantage in non-M3 adult acute myeloid leukemia patients in Egypt. International Journal of Cancer and Biomedical Research, 4(2):87-98.

Möricke A, Zimmermann M, Reiter A, Gadner $H$, Odenwald E, Harbott J, Ludwig W-D, Riehm H, Schrappe M (2005). Prognostic impact of age in children and adolescents with acute lymphoblastic leukemia: data from the trials ALL-BFM 86, 90, and 95. Klinische Pädiatrie, 217(06):310-320.

Mushtaq N, Fadoo Z, Naqvi A (2013). Childhood acute iymphoblastic leukaemia: Experience from a single tertiary care facility of Pakistan. Journal of Pakistan Medical Association, 63(11):1399.

Pizzo PA, Poplack DG (2015). Principles and practice of pediatric oncology: Lippincott Williams \& Wilkins.

Pui CH, Campana D, Pei D, Bowman WP, Sandlund JT, Kaste SC, Ribeiro RC, Rubnitz JE, Raimondi SC, Onciu M (2009). Treating childhood acute lymphoblastic leukemia without cranial irradiation. New England Journal of Medicine, 360(26):2730-2741.

Pui $\mathrm{CH}$, Cheng C, Leung W, Rai SN, Rivera GK, Sandlund JT, Ribeiro RC, Relling MV, Kun LE, Evans WE (2003). Extended follow-up of longterm survivors of childhood acute lymphoblastic leukemia. New England Journal of Medicine, 349(7):640-649.

Pui CH, Pei D, Sandlund J, Ribeiro R, Rubnitz J, Raimondi S, Onciu M, Campana D, Kun L, Jeha $S$ (2010). Long-term results of St Jude Total Therapy Studies 11, 12, 13A, 13B, and 14 for childhood acute lymphoblastic leukemia. Leukemia, 24(2):371-382.

Pui CH, Robison LL, Look AT (2008). Acute lymphoblastic leukaemia. The Lancet, 371(9617):1030-1043.

Pui CH, Sandlund JT, Pei D, Campana D, Rivera GK, Ribeiro RC, Rubnitz JE, Razzouk BI, Howard SC, Hudson MM (2004). Improved outcome for 
children with acute lymphoblastic leukemia: results of Total Therapy Study XIIIB at St Jude Children's Research Hospital. Blood, 104(9):2690-2696.

Pui $\mathrm{CH}$, Yang JJ, Hunger SP, Pieters R, Schrappe $M$, Biondi A, Vora A, Baruchel A, Silverman LB, Schmiegelow K (2015). Childhood acute lymphoblastic leukemia: progress through collaboration. Journal of Clinical Oncology, 33(27):2938.

Rajalekshmy K, Abitha A, Anuratha N, Sagar T (2011). Time trend in frequency of occurrence of major immunophenotypes in paediatric acute lymphoblastic leukemia cases as experienced by Cancer Institute, Chennai, south India during the period 1989-2009. Indian Journal of Cancer, 48(3):310.

Ramot B, Magrath I (1982). Hypothesis: The environment is a major determinant of the immunological sub-type of lymphoma and acute lymphoblastic leukaemia in children. British Journal Haematology, 50(2):183-189.

Rodriguez-Galindo C, Friedrich P, Alcasabas P, Antillon F, Banavali S, Castillo L, Israels T, Jeha S, Harif M, Sullivan MJ (2015). Toward the cure of all children with cancer through collaborative efforts: pediatric oncology as a global challenge. Journal of Clinical Oncology, 33(27):3065.

Schrappe M, Reiter A, Zimmermann M, Harbott J, Ludwig W, Henze G, Gadner H, Odenwald E, Riehm H (2000). Long-term results of four consecutive trials in childhood ALL performed by the ALL-BFM study group from 1981 to 1995. Leukemia, 14(12):2205-2222.
Sidhom I, Mokhles A, Soliman S (2013). Outcome of risk-adapted therapy for pediatric acute lymphoblastic leukemia in Egypt. Journal of Clinical Oncology, DOI: 10.1200/jco.2013.31.15_suppl.10044.

Smith M, Arthur D, Camitta B, Carroll AJ, Crist W, Gaynon P, Gelber R, Heerema N, Korn EL, Link $M$ (1996). Uniform approach to risk classification and treatment assignment for children with acute lymphoblastic leukemia. Journal of Clinical Oncology, 14(1):18-24.

Stary J, Zimmermann M, Campbell M, Castillo L, Dibar E, Donska S, Gonzalez A, Izraeli S, Janic D, Jazbec J (2014). Intensive chemotherapy for childhood acute lymphoblastic leukemia: results of the randomized intercontinental trial ALL IC-BFM 2002. American Society of Clinical Oncology.

Swerdlow SH (2008). WHO classification of tumours of haematopoietic and lymphoid tissues. WHO classification of tumours, 22008:439.

Vrooman LM, Stevenson KE, Supko JG, O'Brien J, Dahlberg SE, Asselin BL, Athale UH, Clavell LA, Kelly KM, Kutok JL (2013). Postinduction dexamethasone and individualized dosing of Escherichia Coli L-asparaginase each improve outcome of children and adolescents with newly diagnosed acute lymphoblastic leukemia: results from a randomized studyDana-Farber Cancer Institute ALL Consortium Protocol 00-01. Journal of Clinical Oncology, 31(9):1202. 